\title{
Characterization of bark extractives of different industrial Indonesian wood species for potential valorization
}

\begin{abstract}
Barks are available as waste material and by-product of wood industry. They have been reported to contain interesting molecules and show some bioactivity such as antioxidant and antifungal. This study aimed at evaluating the amounts of extractives in Acacia mangium (acacia), Paraserianthes falcataria (sengon) and Swietenia mahagoni (mahoni) barks, to evaluate their extractive contents and the presence of potential valuable molecules. The extraction method used soxhlet with four different solvents. Antioxidant activity assays were carried out using methyl linoleate and 2,2-diphenyl-1-picrilhidrazyl (DPPH) and the antifungal activity was determinate by fungal growth inhibitions assays. 5.3\%-18.5\% extraction yields were obtained. All acetone and toluene ethanol extracts show high antioxidant activity by DPPH. The highest antioxidant value obtained by DPPH was obtained for mahoni bark acetone extract with $3.9 \mathrm{mg} / \mathrm{L}$ of EC50, followed by mahoni bark toluene ethanol $6.8 \mathrm{mg} / \mathrm{L}$, acacia bark acetone $7 \mathrm{mg} / \mathrm{L}$, and acacia bark toluene ethanol extract 7.4 $\mathrm{mg} / \mathrm{L}$. Sengon bark extracts had the greatest antifungal activity inhibition. The greatest antioxidant and antifungal activity were obtained with phenolic compounds which were contained in the extracts.
\end{abstract}

Keyword: Antioxidant; Antifungal; Bark; Extractives; Tannin; Valorization 